\title{
LESSONS LEARNED FROM THE IMPLEMENTATION OF THE SEVESO III DIRECTIVE IN THE SLOVAK REPUBLIC
}

\author{
KATARINA HOLLA \\ Faculty of Security Engineering, University of Zilina, Slovakia
}

\begin{abstract}
A new European directive that adapts the area of the major industrial accidents prevention was adopted in 2015 and the EU member states have to transpose this directive to their legal guidelines. The participating parties in Slovakia had an extensive discussion about this topic and the current law is the result of their consensus. The directive has been valid for two years and a few problems from the point of view of the state administration and enterprises have been identified. This article presents the basic conclusions after the guideline's implementation in the Slovak Republic.

Keywords: industrial accidents prevention, risk assessment, SEVESO III Directive, transposition, Slovak Republic.
\end{abstract}

\section{INTRODUCTION}

The history of the European SEVESO directive dates back to 1976 when a major industrial accident in the Italian town of Seveso happened. From 1982 there have been several major industrial accidents which based on the lesson learned from the accidents serve as the starting point for the first directive's revision. The revisions were realised in the years 1996 and 2012. The changes of the year 1996 concerned especially the aim of the directive and a more extensive exchange of information between the member countries. For the first time there were discussed such accidents that cross the borders of the states and are legislatively solved. One of the problems that had been solved in the directive was also the harmonisation of the documents and providing information in the framework of the EU countries. Due to the occurrence of further accidents, e.g. Baia Mare in Romania, in Tolouse in France and studying the carcinogenic substances and materials hazardous for the environment a need of further amendment of the directive was desirable. It happened in 2003. Currently the directive SEVESO III is valid and the SEVESO II ceased to exist on 1st June 2015. The main reason for creating a new guideline was the necessity to respond to the changes in the EU system of classifying the hazardous substances which is reflected in the directive. After investigating the directive it was found out that in spite of the fact the existing provisions fulfilled their purpose and did not require any larger changes a few areas had been determined where revisions were realised.

The following provisions were strengthened by the important changes:

- the access of the general public to information about safety issues, the participation in the decision-making process and access to justice,

- an improved method of collecting, managing, availability and sharing information.

Other changes:

- $\quad$ state stricter standards for carrying out inspections of the premises with the goal to ensure effective realisation and enforcement of the determined rules, 
- the technical adaptations including simplifications which will reduce the unnecessary administrative load.

The EU member states transposed the SEVESO III Directive to their legal environment and the Slovak Republic issued the Law No. 128/2015 Coll., about prevention of major industrial accidents. In the framework of the new legal adaptation it was necessary to change and complete some areas with the goal to clarify and update certain provisions, to improve the executability and at the same time to perceive or even increase the protection level. SEVESO III takes into account the changes in the EU system - in the area of the hazardous substances classification - especially the directive No. 1272/2008 about classification, designation and packaging of the substances and mixtures [1].

Especially the following points were the subjects of the adaptation during transposing the SEVESO III Directive:

- the goals and principles (essentially, they were perceived) - the prevention of the major industrial accidents in the companies working with hazardous substances and limiting their consequences on the human health, environment and property - were not significantly altered,

- the scope of activity was enlarged - storing the natural gas in the underground storages (the natural rock structures and underground spaces), the disposal sites of the mining waste with hazardous substances.

- the exceptions were adapted - the "military objects", cancelling the exception for the Ministry of Interior of the Slovak Republic [2].

These were such facts which the SEVESO II Directive did not adapt. A few terms which fulfil the new criteria and comply with the existing directives and standards (e.g. ISO 31,000 Risk Management) were changed during the process of altering the law [3].

In the framework of the risk assessment and the best practices it was recommended for the companies in connection with identifying the hazards/events to quantify the probabilities, estimating the consequences, assessing the risk and evaluating its acceptability. In connection with the aforementioned things the ministry recommended not to forget about taking measures for reducing the risk and its subsequent management - all of this appeared as one of the problems during processing safety documentation. Similarly during assessing the risks it is possible to use other documentation in connection with the emergency planning which will significantly help processing the emergency plans and security report.

For comparison, in the Czech Republic they perceive the problems after implementing the SEVESO III Directive a little bit differently than in Slovakia. They have more companies/experts for evaluation of safety documentation and this fact results in the high administration load of the individual employees in this area today. Therefore, they have created a network of assessors of the safety documentation and they check the contents and of course, also the fulfilment of the new requirements.

\section{PREVENTION OF MAJOR INDUSTRIAL \\ ACCIDENTS IN THE SLOVAK REPUBLIC}

In Slovakia, there are about 80 SEVESO companies whose location is depicted in Fig. 1. The red colour depicts the $\mathrm{B}$ category (lower tier) companies and green the A ones (upper tier).

It looks like a small number compared with all enterprises of this type (there are approximately 10,000 of them in the EU), however, there are also multinationals here, big chemical companies and automotive enterprises. For comparison, the following table shows the number of these enterprises in other selected EU states (Table 1). 
The number of enterprises did not significantly change after implementing the new directive; however, it could be suitable to re-assess some companies which were indicated to belong under the law but they were omitted - it would be useful to check the amounts of the hazardous substances in their operations.

\section{TRANSPOSITION OF THE SEVESO III DIRECTIVE TO \\ THE LEGAL ENVIRONMENT OF THE SLOVAK REPUBLIC}

In connection with the changes of the EU regulations the member states were obliged to transpose the SEVESO III Directive to their legal guidelines until $31^{\text {st }}$ May 2015. In Slovakia, the transposition was fulfilled by passing the law No. 128/2015 Coll., from $6^{\text {th }}$ May 2015, about prevention of major industrial accidents as amended and subsequently through its implementing regulations - the law of the Ministry of Environment of the Slovak Republic No. 198/2015 Coll., through which some provisions of the law No. 128/2015 Coll., about prevention of major industrial accidents as amended are realised.

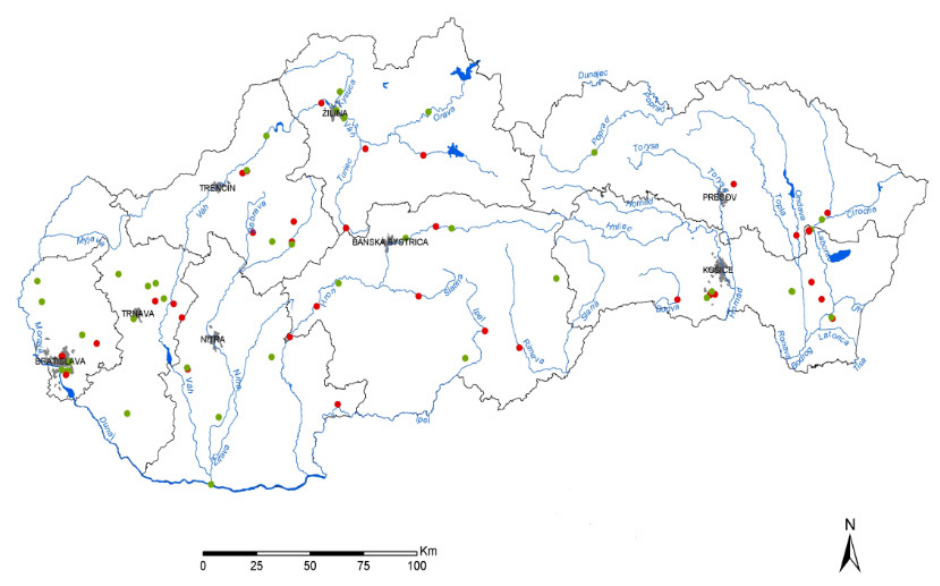

Figure 1: The territorial localisation of the SEVESO companies in Slovakia [4].

Table 1: Number of companies in some EU states.

\begin{tabular}{|c|c|}
\hline Country & $\begin{array}{c}\text { Total number of } \\
\text { SEVESO companies }\end{array}$ \\
\hline Czech Republic & 207 \\
\hline Hungary & 239 \\
\hline Poland & 475 \\
\hline Austria & 148 \\
\hline Belgium & 383 \\
\hline France & 1,178 \\
\hline Germany & 3,264 \\
\hline Italy & 1,112 \\
\hline
\end{tabular}


The further text will bring the assessment of implementing the changes brought by the SEVESO III Directive to Slovakia. There will be analysed the point of view of the state administration, companies but also the often discussed topic of the domino effects which bring a lot of problems especially connected with their assessment to lots of enterprises [5].

\subsection{Informing the general public from the point of view of the state administration}

Informing the general public from the point of view of the lower-tier SEVESO companies (the B type companies) was the most important topic of the aforementioned changes. The permanent access of the public to the selected information was emphasised. This subsequently found its place in the legal regulations:

- The operator of the B type company is obliged to inform the general public which can be concerned by a major industrial accident connected with the company's activity in the location and in the usual way (also repeatedly) about the character of this activity, about the possible risks and measure for their reduction as well as about the required behaviour of the concerned public in the case of a major industrial accident.

- The operator of the B type company will ensure permanent accessibility of information mentioned in the section 1 for the public including the permanent accessibility of the updated list of selected hazardous substances in the company. The corresponding provision relates to the protection of the confidential data [5].

The statistical overview of the method/means for making the information for the Slovak general public in the framework of the previous SEVESO II Directive accessible, see the Table 2.

Some companies made the information for the public available in two ways:

- the passive information method - the web site of the operator, official board at the municipal office, at the entrance to the company, etc.,

- the active information method - the leaflets to the letterboxes, SMS, e-mail, meeting with the citizens, local radio or TV - this method was utilised in a lower extent.

After implementing the SEVESO III Directive the situation in the area of informing the public improved; however, the companies have a problem to publish sensitive information. They consider the problem of informing the public as unnecessary spreading panic or they think the concerned public is not able to understand this information.

Table 2: Methods/means for making information accessible from SEVESO companies to public [4].

\begin{tabular}{|l|l|}
\hline Country & $\begin{array}{l}\text { Total number of } \\
\text { SEVESO companies }\end{array}$ \\
\hline Web site & $100 \%$ \\
\hline Official board of municipal office & $88 \%$ \\
\hline Leaflets & $62.5 \%$ \\
\hline $\begin{array}{l}\text { Information in the company (e.g. } \\
\text { at the entrance) }\end{array}$ & $62.5 \%$ \\
\hline Written information by post & $37 \%$ \\
\hline Radio/television & $37.5 \%$ \\
\hline
\end{tabular}




\subsection{Perception of the companies}

On the other hand, there are the operators: the SEVESO companies. After the implementation they solved various specific problems and a lot of them occur repeatedly in their enterprises. There have been identified duties which reduce the load for the employers according to the newly issued law. One of them was the transformation of the "rescue service" to the service of the rescue response; however, nothing was changed from the point of view of the tasks; the purpose to help quickly and effectively during a major industrial accident remained the same, but:

- $\quad$ its duties were reduced only for the companies where the hazardous substances occur (defined by the law) and belonging to a category of danger,

- there is no more the duty the action to be approved by the corresponding body of the state administration,

- the change of the name definitely solved the problem of confusing this activity with the fire emergency service [6].

The duties increasing the load of the employers are connected especially with the area of the domino effect when the company receives the information of classification to the category. From the point of view of working out the information which increased the load the acquisition of the data about the neighbouring companies presented a problem. In many cases just the identification of the neighbouring companies including the working out of the information about all neighbouring companies, about the specialisation and development which could cause a major industrial accident and the domino effect or which could deteriorate the effects of a major industrial accident was very demanding.

\subsection{Domino effects}

According to the law about prevention of the major industrial accidents the Ministry of Environment of the Slovak Republic determines the companies, the neighbouring enterprises or their groups in the case of which the risks of the major industrial accidents or their consequences could be increased due to their geographical position or their proximity and due to their inventories of the hazardous substances. The Ministry of Environment of the Slovak Republic's definition is based on the information given in the information, security and safety report acquired during the state supervision and the information required from the operator [7].

From the point of view of the existing companies this area is very important. This phenomenon concerns only two emergency cases which possess a sufficient energy potential to initiate the further development of the major industrial accidents in the zone of their undesirable effects (thermal radiation and effects of pressure). It is necessary to realise that also the previous legal form was dealing with the danger of development of a major industrial accident in the company regarding the ambient elements for deteriorating its consequences. In the framework of the risk assessment in the companies also scenarios connected especially with hitting a fragment from the accident of a primary device to a secondary one were worked out and assessed in the documentation according to the previous law. The heat flows due to the requirements of the distances according to the regulations in the area of preventing fires were not taken into account.

From the worldwide experience we can take 255 major industrial accidents which overgrew to a domino effect: 
- the domino effect was initiated by an external event (earthquake, floods, plane catastrophes...) - a $0.31 \%$ probability,

- the domino effect was initiated by an explosion and it caused subsequent fires - a $0.275 \%$ probability,

- the domino effect was initiated by a fire and it caused a subsequent explosion - a $0.275 \%$ probability,

- the domino effect was initiated by a fire and it caused subsequent fires - a $0.178 \%$ probability [7].

The toxic consequences during spreading these accidents due to the domino effect were quantified at the level of $0.4-3.1 \%$, it is much lower that spreading the accident due to flying fragments from a damaged technology.

\section{CONCLUSION}

In spite of the fact the law has been valid for two years there are still some changes under way which are implemented and developed and in a short time the law will have to be amended again in all EU countries. The main changes will be done mainly in REACH and CLP area. This will be mainly concerned with hazardous substances list which will be expanded on new types of hazardous substances but also implementation of uniform assessment criterions for dangerous zones defining and consequences quantification of major industrial accident.

Within Act. About major industrial accidents prevention in Slovak republic there will be definitely needed to correct and improve requirements for safety documentation because some of the important ones are missing here for now and companies have difficulties when fulfilling them.

One of the possible problems is the need to verify if the companies which have not been ranked do not possess a higher quantity of hazardous substances than they claim. From the point of view of informing the general public it is necessary to find a compromise between what the law requires and what the companies consider to be necessary to publish and first of all to find an effective communication method with the concerned general public [8].

The area which requires higher attention is also the area of assessing the domino effects in the companies and especially information which the neighbouring companies are willing or not willing to give to the SEVESO companies.

One of the main challenges for the future in Slovakia is also desperate need for integration all components/areas/stakeholders of industrial accidents prevention therefore it will be expected more intensive cooperation of competent authorities from civil protection, environment and water protection area, integrated rescue system and other emergency services within prevention and preparedness of emergency plans trainings in Seveso establishments. There have been organised several meetings in Joint research centre (JRC) in Ispra in Italy which is responsible for industrial accidents prevention (Seveso III Directive) within European Union. Last meeting was conducted in June and participants from all member states discussed the most important problems regarding Seveso III Directive. One of the main conclusions was that the level of filling all requirements differ from state to state. Another important issue negotiated there was unifying risk assessment approaches and first ideas were discussed related to RAPID- $\mathrm{N}$ and ADAM software product. The future will show if all member states can come into conclusion in this issue. In 2020 JRC will run statistical survey connected to effectiveness of transposition of Seveso III Directive in all member states. 


\section{ACKNOWLEDGEMENTS}

This work was supported by the Slovak Research and Development Agency under the contract No. APVV-0043-10. This article was created as a one of research project outcomes VEGA 1/0749/16 Risk assessment and treatment of industrial processes in relation with integrated security and safety within lower tier establishments.

\section{REFERENCES}

[1] New Act. About major industrial accidents prevention, Online. http://slideplayer.cz/ slide/11273839/, Accessed on: 15 Mar. 2017.

[2] Hollá, K., Complex model for risk assessment of industrial processes. IDRiM Journal, 4(2), pp. 93-102, 2014.

[3] Simak, L. \& Ristvej, J., The present status of creating the security system of the Slovak Republic after entering the European Union. Journal of Homeland Security and Emergency Management, 6(1), Article 20, DOI: 10.2202/1547-7355.1443.

[4] Slovak Agency of Environment: Seveso companies. Online. http://www. enviroportal.sk/environmentalne-temy/starostlivost-o-zp/pzph---prevencia-zavaznychpriemyselnych-havarii.

[5] Čajková, H., Personal interview, Ministry of Environment, Slovak Republic.

[6] Representatives of Seveso establishments from Slovak Republic, Slovak Republic/Czech Republic.

[7] Kandrac, J., Methodological approach for assessment of major industrial accident probability in establishments under Act. of Major industrial accidents prevention, Online. https://www.minzp.sk/files/oblasti/prevencia-priemyselnych-havarii/ metodicka-prirucka.pdf

[8] Holla, K. et. al., Results of survey among SEVESO establishments in the Slovak Republic. Journal of chemical health and safety. 23(2), pp. 9-17, 2016. 